\title{
DESAIN MOBILE SISTEM INFORMASI GEOGRAFIS SEKOLAH GARIS DEPAN (SGD) BERBASIS ANDROID DI PROVINSI GORONTALO
}

\author{
Abd. Malik I Buna \\ mailqloex@gmail.com \\ STMIK Ichsan Gorontalo
}

\begin{abstract}
Abstrak
Sekolah Garis Depan (SGD) merupakan sekolah yang terletak di daerah terluar, terpencil, dan tertinggal (3T), propinsi Gorontalo yang merupakan propinsi baru pemekaran dari Sulawesi Utara masih memiliki \pm 25 sekolah yang termasuk sekolah $3 \mathrm{~T}$. Tujuan penelitian ini adalah merancang suatu Sistem Informasi Geografis agar dapat mengetahui lokasi akurat sekolah yang termasuk 3T serta memberikan informasi tentang kondisi sekolah $3 \mathrm{~T}$ dari segi fasilitas sekolah, guru-guru pengajar dan jumlah siswa. Penelitian ini dilaksanakan di propinsi Gorontalo. Metode analisis sistem yang digunakan adalah metode SDLC (system Development Life Cycle) dengan tahapan yaitu perencanaan sistem (system planning), analisis sistem (system analysis), desain sistem (system design), seleksi sistem (system selection), implementasi sistem (system implementation). Pengujian sistem menggunakan metode test case dengan pendekatan white box testing. Sistem informasi geografis sekolahgaris depan dipropinsi Gorontalo, di desain dan di bangun menggunakan bahasa pemrograman PHP, Google Maps, Android studio dan dreamweaver serta GPS sebagai pendukung penentuan titik koordinat lokasi sekolah. Hasil yang diperoleh yaitu sebuah map/peta digital yang dapat di terapkan di mobile HP/tablet menggunakan sistem operasi android, dilengkapi dengan rute atau jarak yang dapat memudahkan user mengetahui informasi bila mau mencari dan berkunjung ke lokasi.
\end{abstract}

Kata Kunci : Sistem Informasi Geografis, Sekolah Garis Depan, Android.

\section{Pendahuluan}

Provinsi Gorontalo dimekarkan dari Provinsi Sulawesi Utara berdasarkan UU No. 38 tahun 2000. Secara Geografis Wilayah Provinsi Gorontalo berada diantara $0,19^{\circ}-1,15^{\circ}$ Lintang Utara dan $121,23^{\circ}-123,43^{\circ}$ Bujur Timur. Posisi provinsi ini berada di bagian utara Pulau Sulawesi. Secara administrasi Provinsi Gorontalo memiliki batas-batas:

a. Sebelah Utara berbatasan dengan Laut Sulawesi

b. Sebelah Timur berbatasan dengan Provinsi Sulawesi Utara

c. Sebelah Selatan berbatasan dengan Teluk Tomini

d. Sebelah Barat berbatasan dengan Provinsi Sulawesi Tengah

Secara keseluruhan Provinsi Gorontalo tercatat memiliki wilayah seluas $12.215,44 \mathrm{~km}^{2}$. Jika dibandingkan terhadap wilayah Indonesia, luas wilayah provinsi ini hanya sebesar 0,64 \%. Provinsi Gorontalo terdiri dari 5 (lima) kabupaten dan 1 (satu) kota, yaitu: Kabupaten Boalemo, Kabupaten Gorontalo, Kabupaten Pohuwato, Kabupaten Bone Bolango, Kabupaten Gorontalo Utara dan Kota Gorontalo. Luas masing-masing kabupaten/kota adalah:

a. Kabupaten Boalemo seluas: $2.248,24 \mathrm{Km}^{2}(18,4 \%)$

b. Kabupaten Gorontalo seluas: $3.426,98 \mathrm{Km}^{2}(28,05 \%)$.

c. Kabupaten Pohuwato seluas : $4.491,03 \mathrm{Km}^{2}(36,77 \%)$.

d. Kabupaten Bone Bolango seluas : $1.984,40 \mathrm{Km}^{2}(16,25 \%)$

e. Kabupaten Gorontalo Utara seluas : $1.230,07 \mathrm{Km}^{2}(10,07 \%)$

f. Kota Gorontalo seluas : $64,79 \mathrm{Km}^{2}(0,53 \%)$.

Sejak didirikannya, pemerintah di propinsi Gorontalo senantiasa melaksanakan pembangunan di segala sektor, dari segi pendidikan pemerintah propinsi Gorontalo berupaya melaksanakan pembangunan pendidikan di daerah perbatasan dan terpencil lewat program Sekolah Garis Depan (SGD). Sekolah Garis Depan merupakan sekolah yang terletak di daerah terluar, terpencil, dan tertinggal (3T), Berdasarkan informasi dari Dikbudpora bahwa di provinsi Gorontalo memiliki \pm 25 sekolah yang termasuk sekolah garis depan mulai dari tingkat SD sebanyak 17 dan SMP sebanyak 8, permasalahan yang ditemukan bahwa letak sekolah-sekolah yang termasuk terluar, terpencil, dan tertinggal (3T) di propinsi Gorontalo belum dapat diidentifikasi secara tepat posisinya karena sulit untuk dijangkau tempatnya karena letaknya yang jauh dari pusat kota serta minimnya informasi tentang kondisi sekolah-sekolah tersebut, maka dari itu peneliti bermaksud mengangkat penelitian 
dengan judul Desain Mobile Sistem Informasi Geografis Sekolah Garis Depan (SGD) berbasis Android di Provinsi Gorontalo. Penelitian ini diharapkan dapat memberikan informasi tentang letak sekolah $3 \mathrm{~T}$ melalui output berupa peta digital serta dapat memberikan informasi keadaan dan perkembangan sekolah 3T di propinsi Gorontalo.

\section{Metode Penelitian}

Penelitian ini dilakukan di beberapa lokasi, dimana kegiatan observasi dilakukan dibeberapa tempat, yaitu sekolah-sekolah mulai dari SD dan SMP dibeberapa wilayah propinsi Gorontalo, kegiatan selanjutnya akan dilakukan di laboratorium Software Engineering Sistem Informasi STMIK Ichsan Gorontalo untuk eksperimen pengembangan perangkat lunak. Adapun metode yang digunakan dalam analisis dan proses sistem informasi geografis ini adalah metode SDLC (System Development Life Cycle) .

Pengembangan sistem (systems development) dapat berarti menyusun suatu sistem yang baru untuk menggantikan sistem yang lama secara keseluruhan atau memperbaiki sistem yang ada. Sistem yang lama perlu diperbaiki atau diganti disebabkan karena beberapa hal yaitu sebagai berikut :

1. Adanya permasalahan-permasalahan (problem) yang timbul di sistem yang lama. Permasalahan yang timbul dapat berupa : ketidakberesan dan pertumbuhan organisasi.

2. Untuk meraih kesempatan-kesempatan (opportunities)

3. Adanya instruksi-instruksi (directives)

System life cycle adalah sederhana dan masuk akal. Di system life cyle, tiap-tiap bagian dari pengembangan sistem dibagi menjadi beberapa tahapan kerja. Tiap-tiap tahapan ini mempunyai karakteristik tersendiri. Tahapan utama siklus hidup pengembangan sistem dapat terdiri dari tahapan perencanaan sistem (system planning), analisis sistem (system analysis), desain sistem (system design), seleksi sistem (system selection), implementasi sistem (system implementation) dan perawatan sistem (system maintenance). Tahapan-tahapan seperti ini sebenarnya merupakan tahapan di dalam pengembangan sistem teknik (engineering systems)

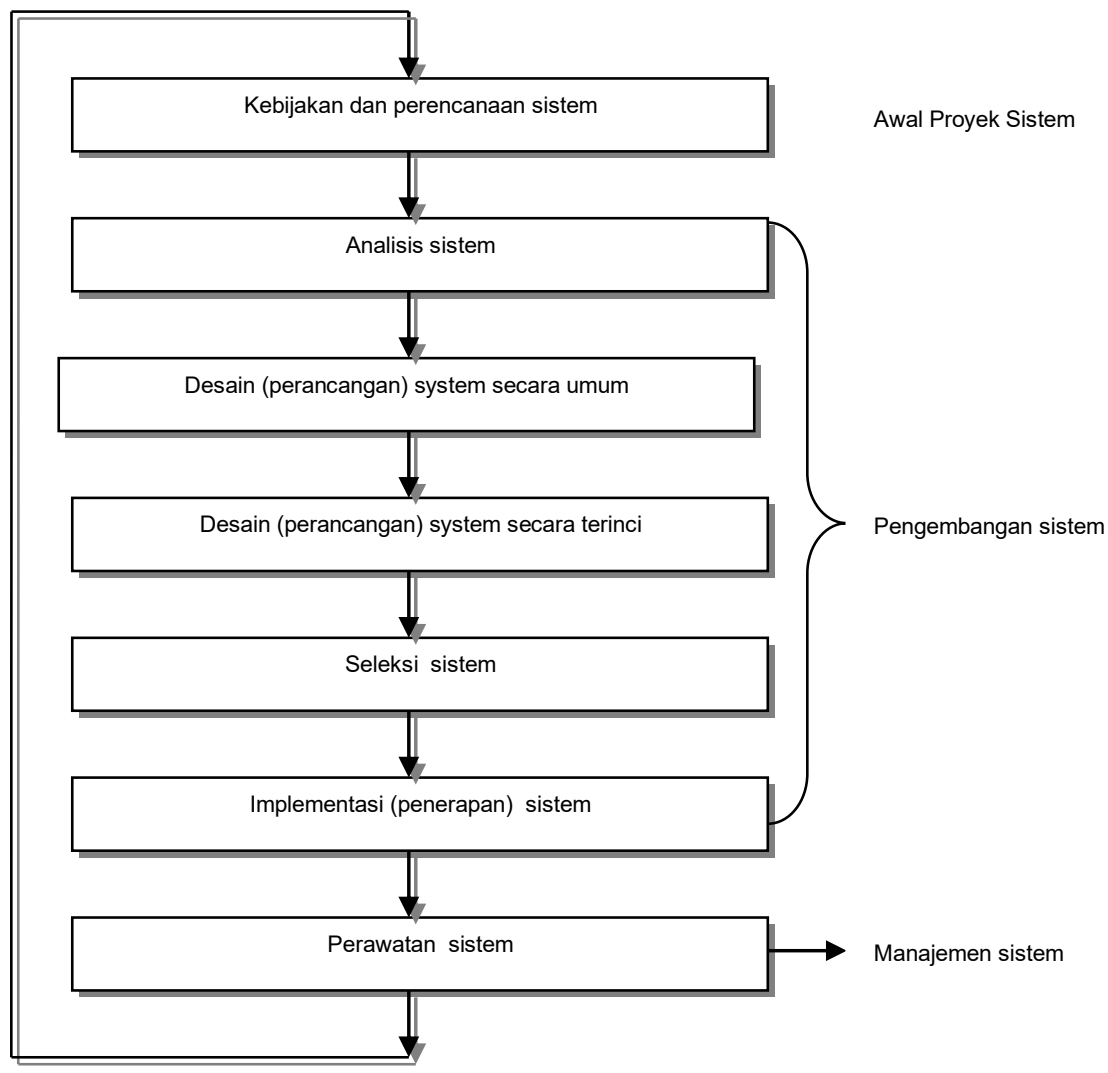

Gambar 1. Siklus hidup pengembangan sistem

Data yang digunakan dalam penelitian ini bersumber dari :

1. Data Sekunder 
Kajian Pustaka (Library Research). Sumber data yang didapatkan dengan mengkaji literatur-literatur, buku-buku dan dari internet yang relevan dengan permasalahan yang dibahas dalam penelitian ini.

2. Data Primer

Penelitian Lapangan (Field Research). Sumber data yang diperoleh dengan cara mengadakan pengamatan langsung terhadap obyek yang diteliti. Untuk mendapatkan data di lapangan maka digunakan teknik :

(1). Observasi, yaitu menghimpun bahan-bahan keterangan yang dilakukan dengan mengadakan pengamatan dan pencatatan serta sistematis terhadap fenomenafenomena yang dijadikan objek pengamatan.

(2). Wawancara, yaitu teknik pengumpulan data dengan menghimpun bahan-bahan keterangan yang dilaksanakan dengan tanya jawab secara lisan, sepihak, berhadapan muka dengan arah tujuan yang telah ditentukan.

Adapun langkah-langkah penelitian yaitu :

1. Pengumpulan dan mempersiapkan data-data berupa : (foto udara, peta geografi, topografi, land system dill).

2. Persiapan data penyelidikan lapangan (ground checking).

3. Persiapan software untuk proses data citra/foto udara, dalam hal ini penulis menggunakan software Google Earth. Kemudian melakukan foto udara dan hasil citra akan digunakan untuk identifikasi blok.

4. Pemilihan software untuk proses digital mapping, dalam hal ini penulis memilih dan menggunakan GIS yaitu Google maps.

5. Penggabungan hasil citra kedalam digital mapping.

6. Desain slstem informasi Geografis untuk sekolah SGD menggunakan PHP, Android studio..

7. Seleksi/pengujian program untuk pelacakan kesalahan, kemudian uji hasil system berdasarkan penilaian responden setelah mendemokan hasil desain program.

8. Bila sudah tidak menemukan kesalahan, sistem informasi tersebut dapat di dokumentasikan dengan dijadikan software berbasis website dan siap di online-kan.

\section{Hasil dan Pembahasan}

\subsection{Desain System}

Use case diagram system mendiskripsikan sebuah interaksi antara satu atau lebih aktor dengan sistem informasi yang dibuat. gambar berikut merupakan use case diagram dari aplikasi

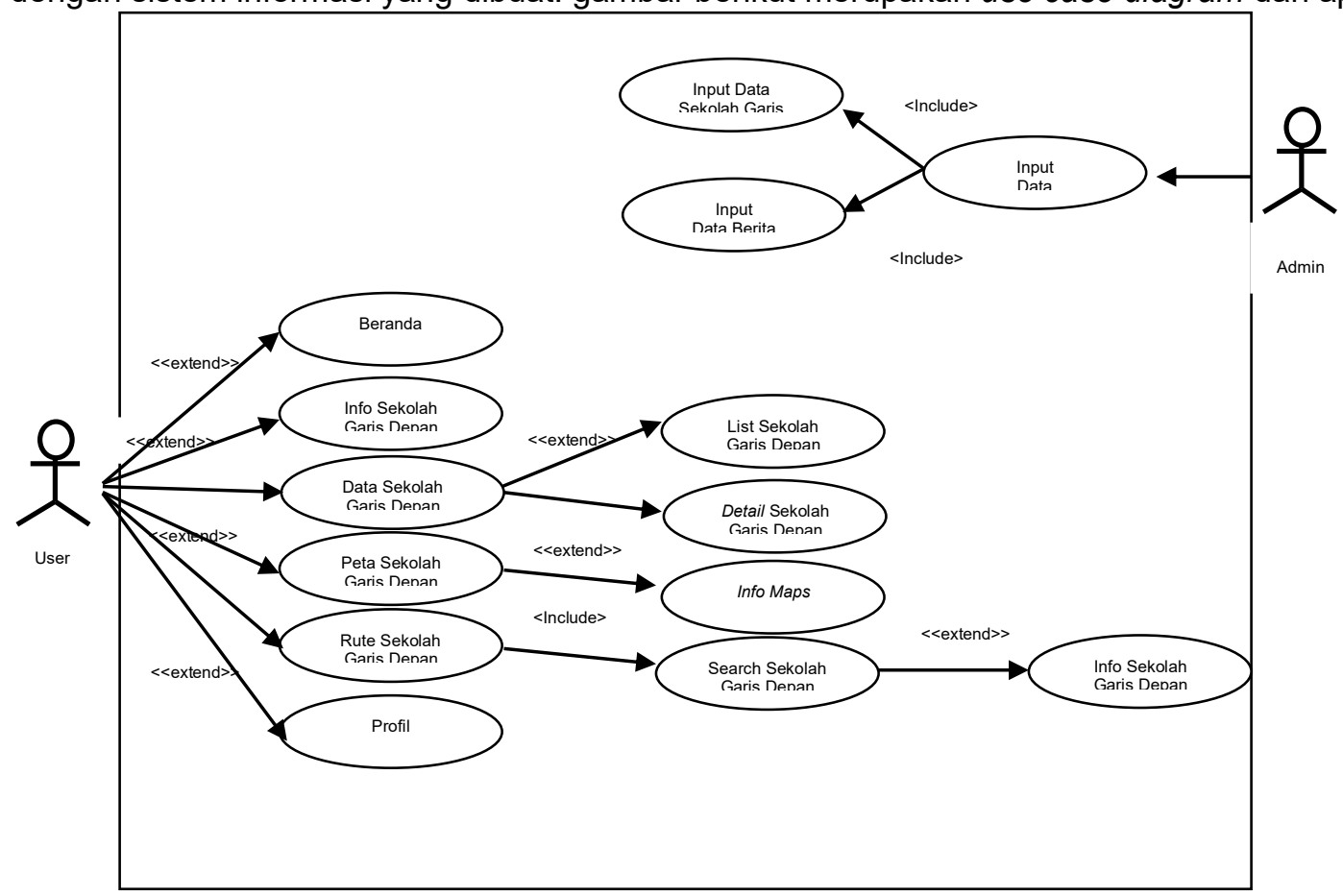

Gambar 2. Use case diagram system 
Use case diagram ini menggambarkan aktifitas utama dalam aplikasi. Berdasarkan gambar di atas bahwa user dapat menggunakan fasilitas aplikasi dalam mengakses menu utama aplikasi, pada menu utama terdapat enam menu, yaitu melihat beranda, info sekolah garis depan, data sekolah garis depan, peta sekolah garis depan, rute sekolah garis depan, dan profil. Pada menu d user dapat melihat semua daftar sekolah garis depan yang berada di propinsi Gorontalo serta melihat detail informasi tentang sekolah garis depan tersebut. Pada use case rute sekolah garis depan, user dapat mencari sekolah serta melihat berapa jarak antara posisi user dan jalan-jala apa saja yang bias dilewati untuk bias sampai di sekolah tersebut.

\subsection{Output Aplikasi SGD}

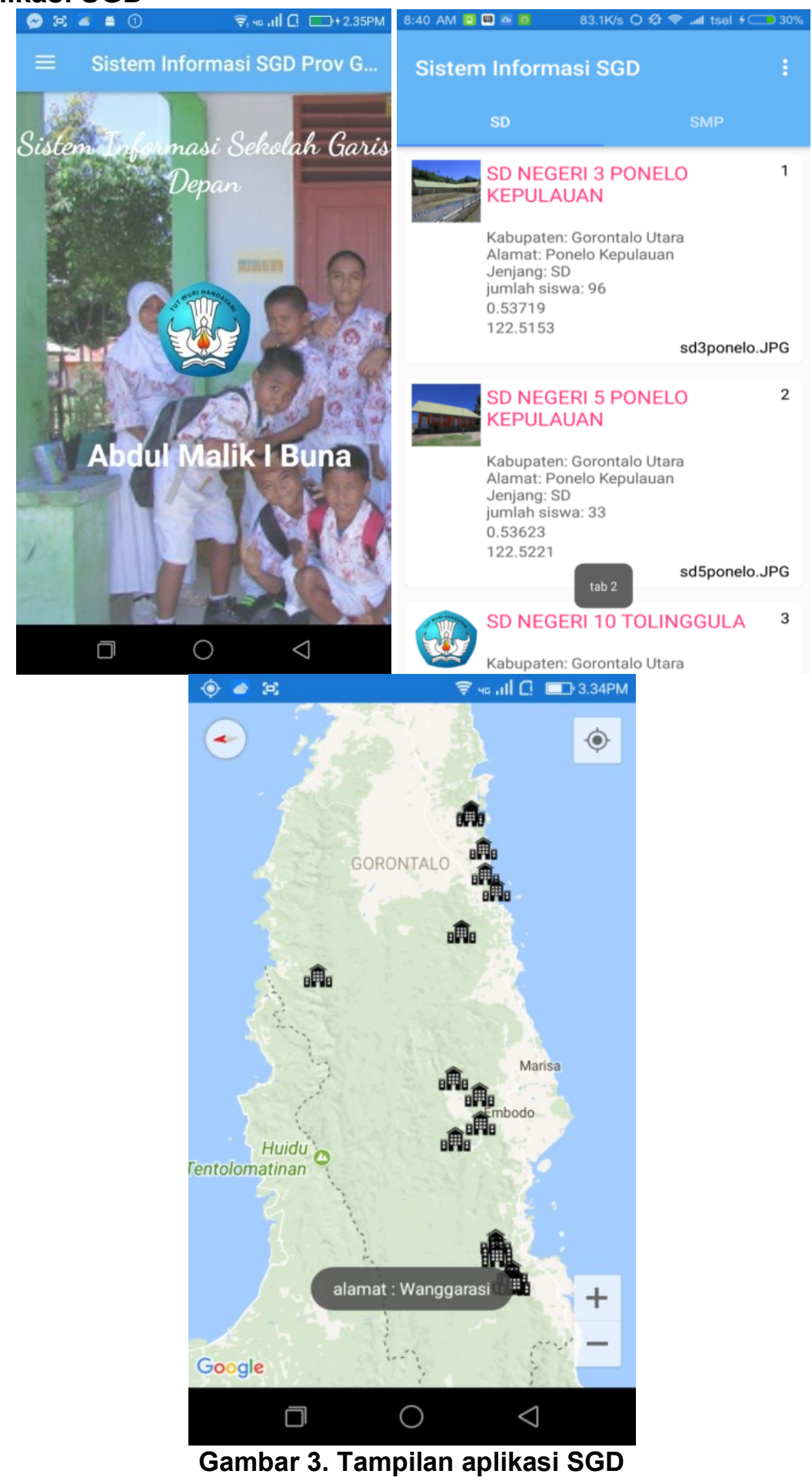

ILKOM Jurnal Ilmiah work is licensed under a CCA-SA 4.0 International License. | 271 


\subsection{Pengujian System}

Tujuan penggunaan white box untuk menguji semua statement program. Penggunaan metode white box dilakukan untuk Memberikan jaminan bahwa semua jalur independen suatu model digunakan minimal satu kali. Menggunakan semua keputusan logis untuk semua kondisi true atau false. Mengeksekusi semua perulangan pada batasan nilai dan operasional pada setiap kondisi. Menggunakan struktur data internal untuk menjamin validasi jalur keputusan.

Gambar dibawah ini adalah salah satu flowchart program aplikasi yang digunakan dalam pengujian system dengan metode test case yaitu white box, kemudian nantinya akan disadur kedalam bentuk flowgraph untuk menghitung nilai Cyclomatic Complexity.

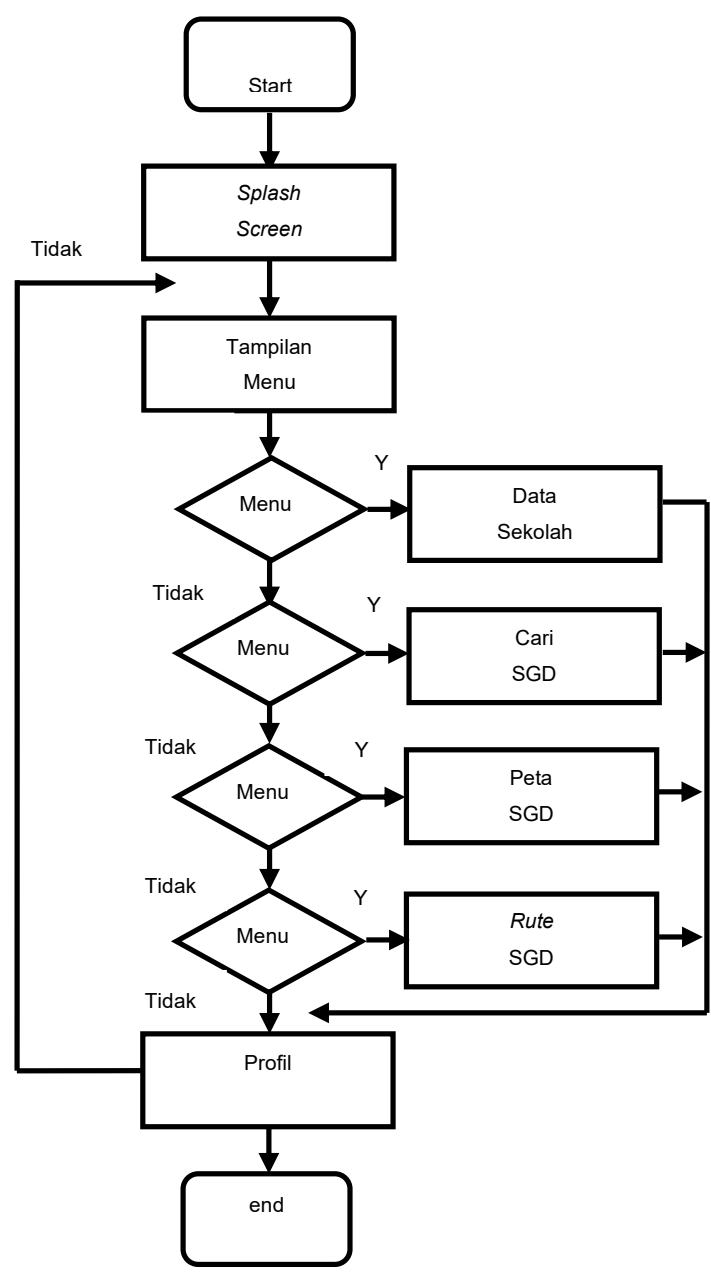

Gambar 4. FlowchartTampilan Aplikasi

Cyclomatic Complexity merupakan sistem pengukuran yang menyediakan ukuran kuantitatif dari kompleksitas logika suartu program. Terdapat 2 persamaan yang digunakan yaitu :

$$
\begin{aligned}
& \mathrm{V}(\mathrm{G})=\mathrm{E}-\mathrm{N}+2 \text { atau } \mathrm{V}(\mathrm{G})=\mathrm{P}+1 \\
& \text { Keterangan : } \\
& \begin{array}{ll}
\mathrm{V}(\mathrm{G}) \quad=\text { Cyclomatic Complexity untuk flow graph } \\
\mathrm{E} \quad=\text { Jumlah Edge (panah) } \\
\mathrm{N} \quad=\text { Jumlah Node (lingkaran) } \\
\mathrm{P} \quad=\text { Jumlah predikat node }
\end{array}
\end{aligned}
$$

Untuk pengujian flowchart program aplikasi diatas diketahui bahwa :

$$
\begin{array}{lrl}
\text { Region } & (\mathrm{R}) & =6 \\
\text { Edge } & (\mathrm{E}) & =17 \\
\text { Node } & (\mathrm{N}) & =13 \\
\mathrm{P} & =\mathrm{R}-1 \\
& & =6-1
\end{array}
$$


Predicate node $(P)=5$

a. $\mathrm{V}(\mathrm{G})=\mathrm{E}-\mathrm{N}+2$

$=17-13+2$

$=6$

b. $V(G)=P+1$

$=5+1$

$=6$

c. Cyclomatic Complexity (CC)

$\mathrm{R} 1, \mathrm{R} 2, \mathrm{R} 3, \mathrm{R} 4, \mathrm{R} 5, \mathrm{R} 6=\mathbf{6}$

d. Independent Path yaitu :

Path 1 : 1-2-3-4-5-6-7-8-13-3

Path 2 : 1-2-3-4-5-6-7-8-13

Path 3 : 1-2-3-4-9-8-13

Path 4 : 1-2-3-4-5-10-8-13

Path 5 : 1-2-3-4-5-6-11-8-13

Path 6 : 1-2-3-4-5-6-7-12-8-13

Berdasarkan hasil pengujian White Box Testing diatas dapat disimpulkan bahwa Flowchart benar. Hasil uji diatas menunjukkan penerapan metode test case dengan penerapan White Box Testing dapat menghasilkan sistem dan proses perulangan pada flowchart di sistem efektif dan efisien.

\section{Kesimpulan dan Saran}

Proses analisa dan desain Sistem Informasi Geografis Pemetaan Lokasi Sekolah Garis Depan Berbasis Android Di Provinsi Gorontalo berjumlah \pm 25 sekolah yang terdiri dari SD sebanyak 17 dan SMP sebanyak 8 sekolah, berdasarkan hasil ujian pengujian dengan mengunakan test case membuktikan bahwa sistem informasi geografislokasi sekolah garis depan ini lebih efektif dan efisien dibandingkan peta secara manual. Berikut kesimpulan hasil pengujian : $\mathrm{V}(\mathrm{G})=17-13+2=6$, $\mathrm{V}(\mathrm{G})=5+1=6$, Cyclomatic Complexity $(\mathrm{CC})$ yaitu R1,R2,R3,R4,R5,R6 = 6. Berdasarkan hasil tersebut, diperoleh kesimpulan bahwa sistem informasi geografis berbasis android memudahkan dalam pencarian lokasi sekolah garis depan baik dalam hal kemudahan, kecepatan, ketepatan, maupun keamanan data.Sistem yang dirancang akan bersifat sistem menu sehingga lebih mudah digunakan.

\section{Daftar Pustaka}

[1] Arikunto, 2010. Prosedur Penelitian suatu pendekatan praktik, Jakarta: PT. Rineka. Cipta.

[2] Aziz, M.ST, dan Pujiono, S. 2006, Geographic Information System. Yogyakarta.

[3] Erna Kharistiani dan Eko Ariwibowo, 2013, Sistem Informasi Geografis Pemetaan Potensi Sma/Smk Berbasis Web Di Kabupaten Kebumen, Universitas Ahmad Dahlan, Yogyakarta.

[4] Peraturan Daerah Kabupaten Gorontalo Nomor 20 Tahun 2003 tentang Struktur Organisasi dan Tata Kerja Perangkat Daerah Pemerintah KabupatenGorontalo.

[5] Sasrimita, 2015, Sistem Informasi Geografis Pemetaan Sekolah Di Kecamatan Tanjung Batu Berbasis Mobile. Universitas Islam Negeri Raden Fatah. Palembang.

[6] Dhani, 2012. Data Spasial. Andi Offset, Yogyakarta.

[7] Fowler, Martin.2013.UML Distilled. Yogyakarta : Andi.

[8] Munawar. 2012. Pemodelan Visual dengan UML.Yogyakarta: Graha IImu.

[9] Prahasta, 2011. Sistem Informasi Geografis : Konsep-Konsep Dasa rnformatika. Bandung.

[10] Pressman S. R, 2012, Rekayasa Perangkat Lunak Pendekatan Praktisi buku 1. PT. Gramedia, Jakarta

[11] Ridwanaz, 2012. Pengertian Penelitian Deskriptif. Jakarta: Erlangga 